\title{
CFD Investigation of Parameters Affecting Oil-Water Stratified Flow in a Channel
}

\author{
Satish Kumar Dewangan \\ Mechanical Engineering Department, \\ National Institute of Technology Raipur, Chhattisgarh, India. \\ Corresponding author: skdewangan.mech@nitrr.ac.in \\ Santosh Kumar Senapati \\ Department of Mechanical Engineering, \\ Indian Institute of Technology Kharagpur, West Bengal, India. \\ E-mail: senapatis431@gmail.com

\section{Vivek Deshmukh} \\ Mechanical Engineering Department, \\ National Institute of Technology Raipur, Chhattisgarh, India. \\ E-mail: vivekd1991@ymail.com
}

(Received October 21, 2019; Accepted April 12, 2020)

\begin{abstract}
Stratified flow is a common occurrence for various internal flow based industrial multiphase flow patterns. This involves fully or partially well-defined interface which continuously evolve with space and time. Hence stratified flow analysis essentially involves proper interface capturing approach. The present work focuses on the numerical analysis of oil-water stratified pattern using the Coupled level set and volume of fluid method (CLSVOF) in ANSYS Fluent in a twodimensional channel. The work involves predicting the effect of density ratio, kinematic viscosity and surface tension coefficient on the mixture velocity and total pressure changes. At outset, the final conclusions may be gainfully employed in oil transportation pipeline, chemical industries and in pipeline flow control administration, etc.
\end{abstract}

Keywords- Stratified flow, Multiphase flow, Level set method, Volume of fluid, CLSVOF.

Nomenclature
\begin{tabular}{|l|l|}
\hline Symbols & Greek letters \\
\hline$k=$ Thermal conductivity of fluid $(\mathrm{W} / \mathrm{m}-\mathrm{k})$ & $\rho=$ Density of fluid \\
\hline$C_{p}=$ Specific heat of fluid $(\mathrm{J} / \mathrm{kg}-\mathrm{K})$ & $\mu=$ Viscosity of fluid \\
\hline$P=$ Pressure $(\mathrm{pa})$ & $\sigma=$ Surface tension coefficient \\
\hline$\dot{m}=$ mass flux $\left(\mathrm{Kg}-\mathrm{s}^{-1} / \mathrm{m}^{2}\right)$ & $\alpha=$ contact angle \\
\hline$r=$ Volume fraction & $\tau=$ shear stress \\
\hline$V_{m}=$ Mixture velocity $(\mathrm{m} / \mathrm{s})$ & $\phi=$ Level set function \\
\hline$V_{o}=$ Superficial velocity of oil $(\mathrm{m} / \mathrm{s})$ & $\delta=$ Dirac delta function \\
\hline$V_{w}=$ Superficial velocity of water $(\mathrm{m} / \mathrm{s})$ & $\Gamma=$ interface \\
\hline$B=$ Body force per unit volume & $\theta=$ inlet to wall temperature ratio \\
\hline$x=$ space coordinate & $\epsilon=$ Half of the thickness of interface \\
\hline$t=$ time $(\mathrm{s})$ & \\
\hline$\hat{n}(\phi)=$ Unit vector normal to interface & Abbreviations \\
\hline$S_{€}=$ smoothed sign function & CLSVOF: Coupled level set and volume of fluid \\
\hline$\Delta X \Delta Y=$ size of control volume in $x$ and $y$ directions & LSM: Level set method \\
\hline$H=$ Heaviside function or Unit step function & VOF: Volume of fluid \\
\hline$\partial P / \partial x=$ pressure gradient $(P a / m)$ & PISO Pressure implicit with splitting of operator \\
\hline Subscripts & PRESTO: PREssure STaggering Option \\
\hline$m=$ mean & DGLSM: Dual Grid LSM \\
\hline $1 \& 2=$ phase 1 \& phase 2 & CFD: Computational fluid dynamics \\
\hline
\end{tabular}


International Journal of Mathematical, Engineering and Management Sciences

Vol. 5, No. 4, 602-613, 2020

https://doi.org/10.33889/IJMEMS.2020.5.4.049

\section{Introduction}

When two or more fluids simultaneously flow through a conduit, they can configure themselves in several ways. One such flow configuration is the stratified flow configuration which is characterized by the interface (well-defined / diffused) between the phases. Proper capturing of the interface is essential in the analysis of stratified flow analysis as discontinuity of fluid properties, and involvement of surface tensions forces there. This behooves that the computational methods employed in stratified flow analysis must be able to detect the interface beginning \& growth. The stratified flow pattern is mainly observed for low flow rate when the pipe is horizontal or nearly horizontal. Stratified flow pattern can also be divided into subcategories such as: smooth stratified flow, wavy stratified flow, wavy with dispersion of one phase into other. Based on the amplitude of the wave Ayati et al. $(2014,2015)$ and Goldstein et al. (2015) have given clear categories of the wavy stratified flow pattern. Such flow pattern occurs because of the displacement of one fluid by another. The buoyancy force is balanced by the viscous force. The computational techniques that are being used for capturing the interface are level set method (LSM) and volume of fluid method (VOF). The biggest advantage of LSM is that it represents the interface implicitly by a mathematical function known as level set function, thus explains all the interfacial phenomena such as merging, and breaking up, cup formation etc. naturally without any extra care. However, the method has a serious demerit, which comes in terms of mass error. Mass error can be defined as the unwanted increase or decrease of mass caused due to numerical error. On the other hand, VOF ensures mass conservation always. However, it uses interpolation schemes to represent the interface. Also, it cannot explain the interfacial phenomena so easily like LSM. Thus, the new method, namely CLSVOF method utilizes the advantages of LSM and VOF methods and thus proves itself to be better than both.

Elseith (2001) has studied the behavior of simultaneous oil-water flow in horizontal pipes. Stratified and dispersed flow pattern were obtained. The effect of mixture velocity and inlet water cutoff on flow pattern transition was studied. The pressure gradient, water volume fraction, axial velocity and turbulent quantities were measured and compared for different combination of inlet mixture velocity and water volume fraction for both stratified and disperse flow pattern. Yap et al. (2006) has done immiscible flow through channel. Rodriguez and Baldani (2012) have, experimentally and numerically, examined the effect of superficial oil velocities, water velocities and pipe inclination angles on the pressure gradient and volume fraction for oil-water stratified flow. Desamala et al. (2014) have performed a CFD analysis of the slug, stratified and flow patterns for oil-water two phase flows in horizontal channel using Volume of fluid method. Avila and Rodriguez (2014) have obtained the pressure gradient for oil-water stratified flow using CFD. Datta et al. (2011) have studied the two-phase stratified flow through plane channel (including and excluding phase change occurrence) subjected to variable thermal conditions. Gada and Sharma $(2011,2012)$ have introduced a novel dual grid LSM (DGLSM) for two phase stratified flow simulation and successfully applied it in the analysis of two phase-stratified flow in horizontal and inclined channel. The method was found to be more accurate; however, increased the computational time. Das et al. (2015) have examined the phase viscosity ratio effects on the laminar stratified flow pattern in a circular cross-section pipe using LSM. Li et al. (2015) have investigated the stratified flow in presence of three phases using the LSM. Joyce and Soliman (2016) have analyzed stratified flow in pipe junctions and Lee et al. (2015) have done the quantative analysis of such flow cases.

The present work involves prediction of the effect of density ratio $\left(\mathrm{k}=\frac{\text { Density of oil }}{\text { density of water }}\right)$, kinematic viscosity $(v)$ of oil and surface tension coefficient $(\sigma)$ on the mixture velocity and total pressure of 
stratified flow pattern using CLSVOF. The simulations have been done in a two-dimensional rectangular channel in transient mode. All results have been obtained only after the steady state is reached. The brief detail of cases is enumerated in Table 1.

Table 1. Brief details of various cases simulated

\begin{tabular}{|c|c|c|c|c|c|}
\hline \multicolumn{2}{|c|}{$\begin{array}{c}\text { Case 1: } \\
\text { Prediction of effect of density } \\
\text { ratio, }(\mathrm{k})\end{array}$} & \multicolumn{2}{c|}{$\begin{array}{c}\text { Case 2: } \\
\text { Prediction of effect of kinematic viscosity } \\
(\mathrm{v}) \text { of oil }\end{array}$} & \multicolumn{2}{c|}{$\begin{array}{c}\text { Case 3: } \\
\text { Prediction of effect of kinematic viscosity } \\
(\mathrm{v}) \text { of oil }\end{array}$} \\
\hline S.N. & Density ratio & S.N. & Kinematic viscosity $(\mathrm{v})$ of oil $\left(\mathrm{m} / \mathrm{s}^{2}\right)$ & S.N. & $\begin{array}{c}\text { Surface tension coefficient }(\sigma) \\
\left(\mathrm{N} / \mathrm{m}^{2}\right)\end{array}$ \\
\hline $\mathrm{a}$ & 0.60 & $\mathrm{a}$ & $8.91 \times 10^{-07}$ & $\mathrm{a}$ & 0.0240 \\
\hline $\mathrm{b}$ & 0.89 & $\mathrm{~b}$ & $1.52 \times 10^{-04}$ & $\mathrm{~b}$ & 0.0430 \\
\hline $\mathrm{c}$ & 1.0 & $\mathrm{c}$ & $1.21 \times 10^{-04}$ & $\mathrm{c}$ & 0.0622 \\
\hline
\end{tabular}

\section{Mathematical Modeling}

ANSYS-Fluent manuals (2012), Senapati and Dewangan (2017), Dewangan et al. (2020) have given a handsome detail of the mathematical modelling of governing equations for the two-phase wavy stratified flow using CLSVOF method. The CLSVOF method combines the best features of LSM and VOF methods, making superior of either.

The volume fraction advection equation for VOF method is,

$$
\begin{aligned}
& \frac{\partial\left(\rho r^{k}\right)}{\partial t}+V \cdot \nabla r^{k}=0, \text { for } k=1,2,3 \ldots \ldots,(n-1) \\
& \sum_{k=1}^{n} r^{(k)}=1, \text { for } k=1,2,3 \ldots \ldots,(n-1)
\end{aligned}
$$

Here $\mathrm{n}$ refers to number of fluid and $r^{k}$ refers to the volume fraction of kth fluid. The volume fraction $r$ is 0 or 1 signified a single-phase fluid filled cell whereas $0<r<1$ in multiphase filled cells. The identification of the interface in the computational domain while simulation tracked by a Level set function $(\phi)$ all over the domain. Zero value of this functions indicates the interface existence at that location.

Mathematically it is given as,

$\phi=\left\{\begin{array}{c}+d, x>0 \\ 0, x=0 \\ -d, x<0\end{array}\right.$

Here, $d$ is the normal distance measured from the interface.

The LSM deploys the Heaviside function $H(\phi) \&$ the Dirac delta function $\delta(\phi)$, in order to newly express the governing equations for LSM (Gada and Sharma, 2009). These are expresses as, 


$$
\begin{aligned}
& H(\phi)= \begin{cases}0 & \text { if } \phi<€ \\
\frac{\phi+€}{2 €}+\frac{1}{2 \pi} \sin \left(\frac{\phi \pi}{€}\right) & \text { if }|\phi| \leq € \\
1 & \text { if } \phi>€\end{cases} \\
& \delta(\phi)= \begin{cases}\frac{1}{2 €}+\frac{1}{2 €} \cos \left(\frac{\phi \pi}{€}\right) & \text { if } \phi=0 \\
0 & \text { otherwise }\end{cases}
\end{aligned}
$$

By the deployment of Heaviside function for LS function the mean fluid propertied are computed. On the other hand, the Dirac delta function is devised for accounting the effect of surface tension or interfacial mass transfer etc. for deriving mathematical model, as it represents the ratio of surface area of cell to the volume of cell.

The continuity equation, level set advection equation, momentum conservation equation, and reinitialization equation are presented in equations (6) - (9), respectively.

$$
\begin{aligned}
& \nabla \cdot \vec{u}=\left(\frac{1}{\rho_{2}}-\frac{1}{\rho_{1}}\right) \dot{m} \frac{\Delta S i}{\Delta V}=\left(\frac{1}{\rho_{2}}-\frac{1}{\rho_{1}}\right) \dot{m} \delta(\phi) \\
& \frac{\partial \phi}{\partial t}+\vec{u}_{t} \cdot \nabla \phi=0 \\
& \frac{\partial\left(\rho_{m} \vec{u}\right)}{\partial t}+\nabla \cdot\left(\rho_{m} \vec{u} \vec{u}\right)=-\nabla P+\nabla \cdot \mu_{m}\left(\nabla \cdot \vec{u}+\nabla \cdot \vec{u}^{T}\right)+\sigma k \hat{n} \delta(\phi)+\vec{B} \\
& \frac{\partial \phi}{\partial t_{s}}+S_{€}\left(\phi_{0}\right)(|\nabla \phi|-1)=0
\end{aligned}
$$

Here $t_{s}$ is the pseudo time, $S_{€}\left(\phi_{0}\right)=\frac{\phi_{0}}{\sqrt{{\phi_{0}{ }^{2}}_{€^{2}}}}$ is the smoothed sign function. The solution of the Equation (9) ensures $|\nabla \phi|=1$.

\section{Numerical Formulation}

\subsection{Procedural Outline}

The computational domain chosen for the present work is a two-dimensional rectangular domain with separate inlets for oil and water. The domain has been divided into four sections namely: oil inlet, water inlet, test section and outlet. Water and oil entries are shown in Figure 1. The full domain has been discretized using quadrilateral control volumes cells (Figure 2) in order to capture the effect of surface tension precisely. From the grid independent study mesh with 56502 control volumes have been chosen.

First, the entire channel has been taken as occupied with only water only. As the simulation begins oil (primary phase) and water (secondary phase) is introduced through the respective inlets. A first order implicit transient (with variable time stepping) pressure-based planer solver has been taken with gravity activation along -ve y-axis \& atmospheric operating pressure. VOF based multiphase model has been considered with LSM and surface tension force modeling options. Inlet velocities $\mathrm{V}_{\mathrm{o}}$ and $\mathrm{V}_{\mathrm{w}}$ has been set to 0.2 and $0.23 \mathrm{~m} / \mathrm{s}$, respectively. No slip boundary condition is set at wall. 
Pressure outlet boundary condition is set at outlet. Contact angle is set to value $8.5^{0}$ for all cases. Pressure-velocity linkage has been resolved using PISO algorithm. The various discretization schemes have been PRESTO, geo-reconstruct, and power law schemes for pressure, volume fraction and momentum (all with $10^{-04}$ residuals), respectively - with default under relaxations. While simulations Courant number has been maintained within 3 and reported results have been conserved after the achievement of steady state situation.

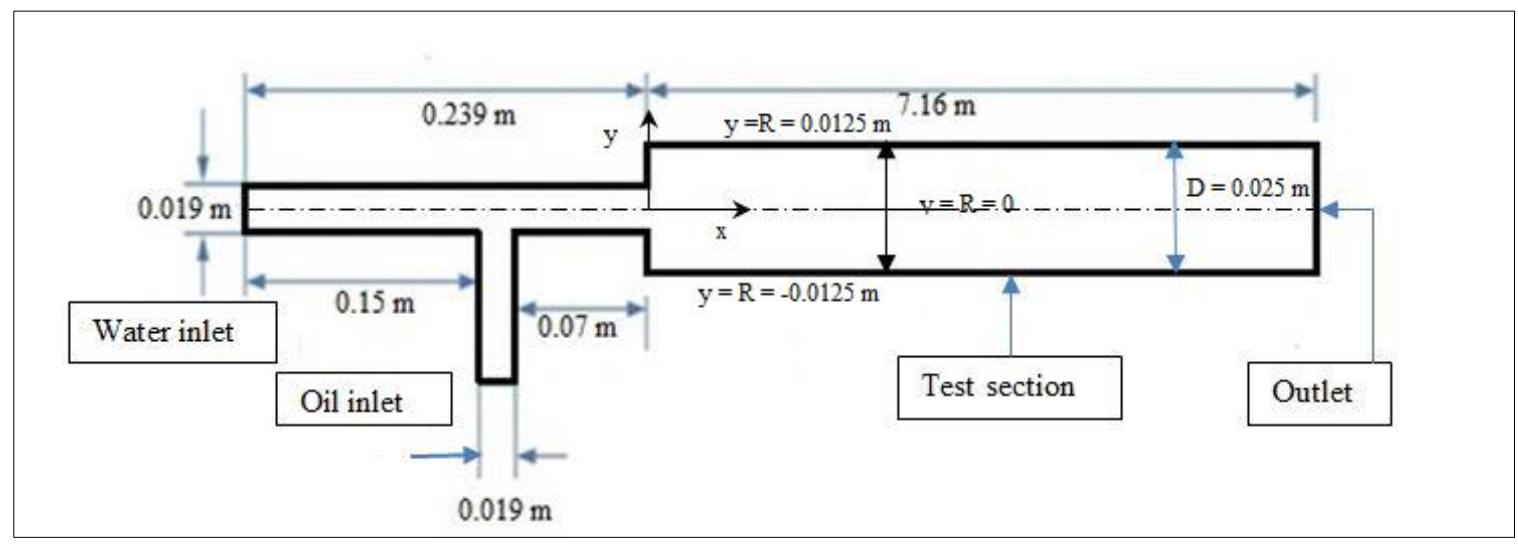

Figure 1. Plan representation of 2D channel domain

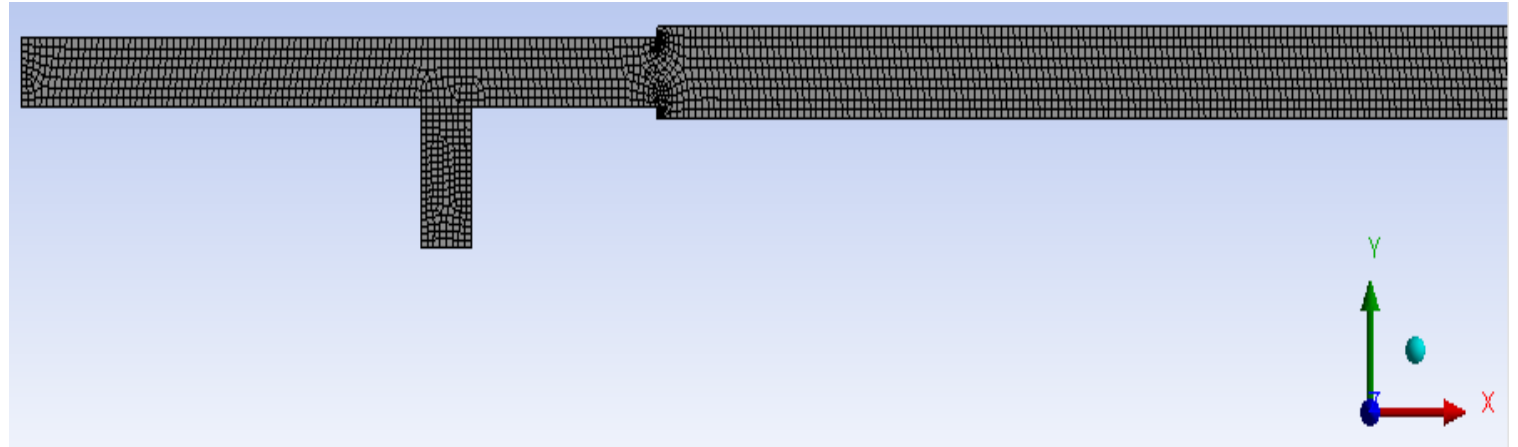

Figure 2. Mesh arrangement of 2D channel domain

\subsection{Mesh Refinement Study and Experimental Validation}

Table 2 shows the details of cell distribution in various meshes. Figure 3 shows the diametric variation for all the meshes. The diametric variation of oil volume fraction for meshes with 48152 cells, 56502 cells and 69570 cells are almost identical. More particularly the oil volume fraction graph of fourth (56502 cells) and fifth mesh (69570 cells) are almost overlapping. Thus, the fifth mesh with 56502 numbers of control volumes has been selected as the optimum mesh for simulation. The present computations have been validated with researches of Elseith (2001). The pipe diameter has been taken as $0.05575 \mathrm{~m}$ and pipe length has been taken as $5 \mathrm{~m}$ complying fully developed flow. The mixture velocity $\left(V_{m}\right)$ has been taken as $0.67 \mathrm{~m} / \mathrm{s}$. Figure 4 indicates a satisfactory agreement is achieved between the computational result and experimental result. 
International Journal of Mathematical, Engineering and Management Sciences

Vol. 5, No. 4, 602-613, 2020

https://doi.org/10.33889/IJMEMS.2020.5.4.049

Table 2. Details of different grids used in mesh independent study

\begin{tabular}{|c|c|c|c|}
\hline $\begin{array}{c}\text { Mesh } \\
\text { no. }\end{array}$ & $\begin{array}{c}\text { Number of cells along horizontal portion of } \\
\text { test section }\end{array}$ & $\begin{array}{c}\text { Number of cells along vertical portion(outlet) } \\
\text { of test section }\end{array}$ & Number of cells \\
\hline 1 & 2996 & 11 & 27953 \\
\hline 2 & 3445 & 20 & 35830 \\
\hline 3 & 4194 & 30 & 48154 \\
\hline 4 & 4494 & 40 & 56502 \\
\hline 5 & 5093 & 50 & 69570 \\
\hline
\end{tabular}

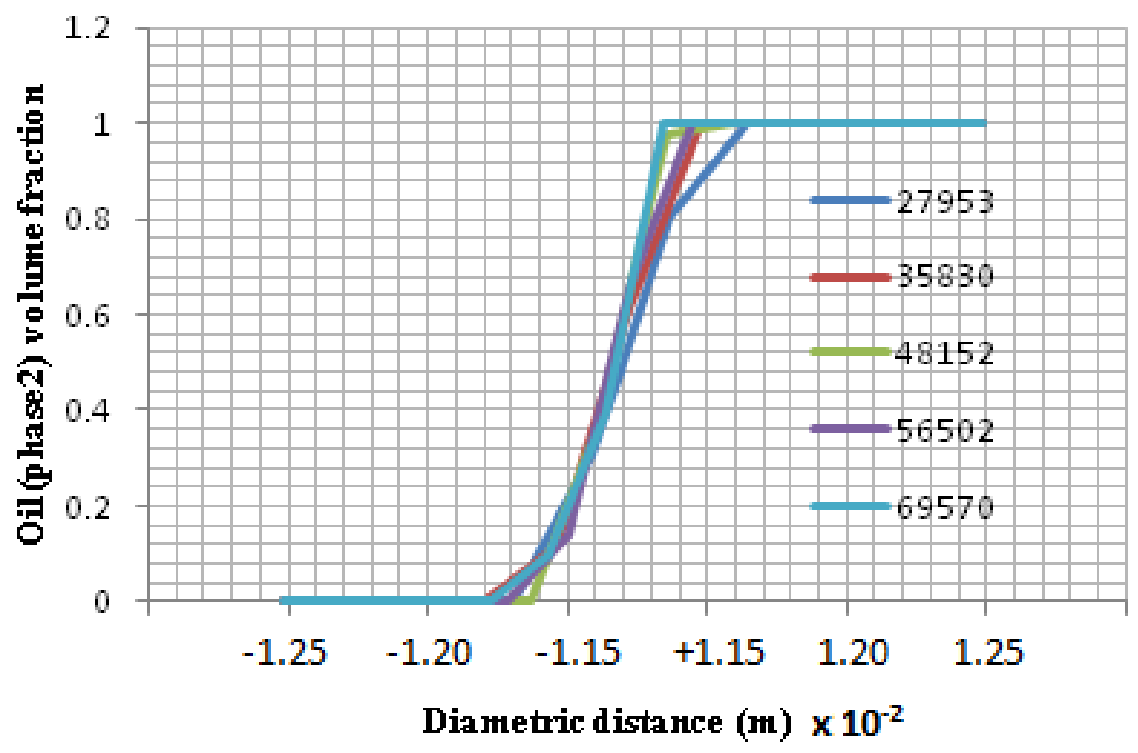

Figure 3. Diametric variation of oil volume fraction for different mesh size

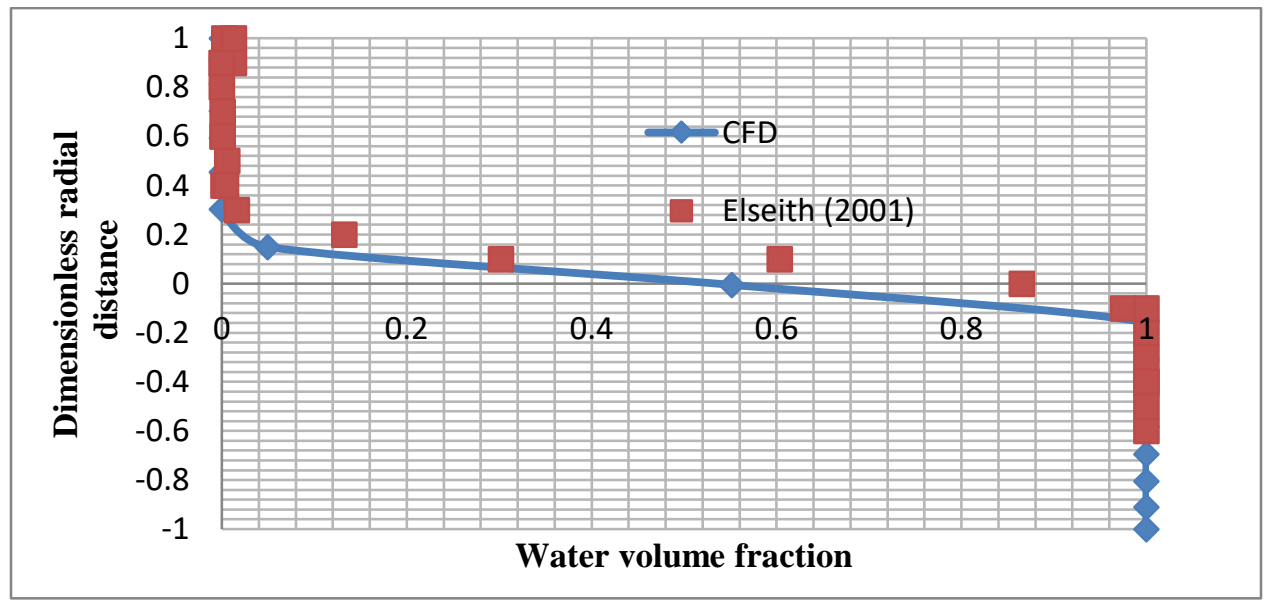

Figure 4. Comparison of radial variation of water volume fraction of computational work with the experimental work of Elseith (2001) 
International Journal of Mathematical, Engineering and Management Sciences

Vol. 5, No. 4, 602-613, 2020

https://doi.org/10.33889/IJMEMS.2020.5.4.049

\section{Results and Discussions}

Density ratio, kinematic viscosity of oil and surface tensions are some of the important parameters pertaining to any flow pattern. Thus, the present investigation is devoted in exploring individual consequence of these parameters on the diametric variation of mixture velocity and total pressure. In each case, only one parameter has been varied keeping other parameters constant.

The diametric distance in all cases has been measured from a datum. The test section lies at a height of $6.55 \mathrm{~m}$ from the datum. From the Figure 5, which is showing the diametric variation of mixture velocity with density ratio (r), it may be observed that first the mixture velocity increases with the diametric distance, then attains a maximum value and again decreases. The velocity takes its maximum value mostly in the diffused interface region. Also, with the increase in density ratio, the maximum velocity occurs at a higher diametric distance. In addition, the maximum velocity is observed for $r=0.6$. For $r=0.6$ the velocity variation is steep initially and after the attainment of maximum value the variation is gradual. However, the diametric variation of velocity is found to be more gradual at higher density ratio.

The density ratio (r) vs. diametric variation of total pressure plot has been revealed in Figure 6 . For a given density ratio total pressure of mixture increases with increase in diametric distance attains maxima then decreases. For $r=0.6$ negligible variation in total pressure is found at the top portion of channel. However, at higher density ratios total pressure is found to decrease with increase in the diametric distance at the top portion of channel. Maximum value of pressure shifts to a higher diametric distance with the increase in density ratio.

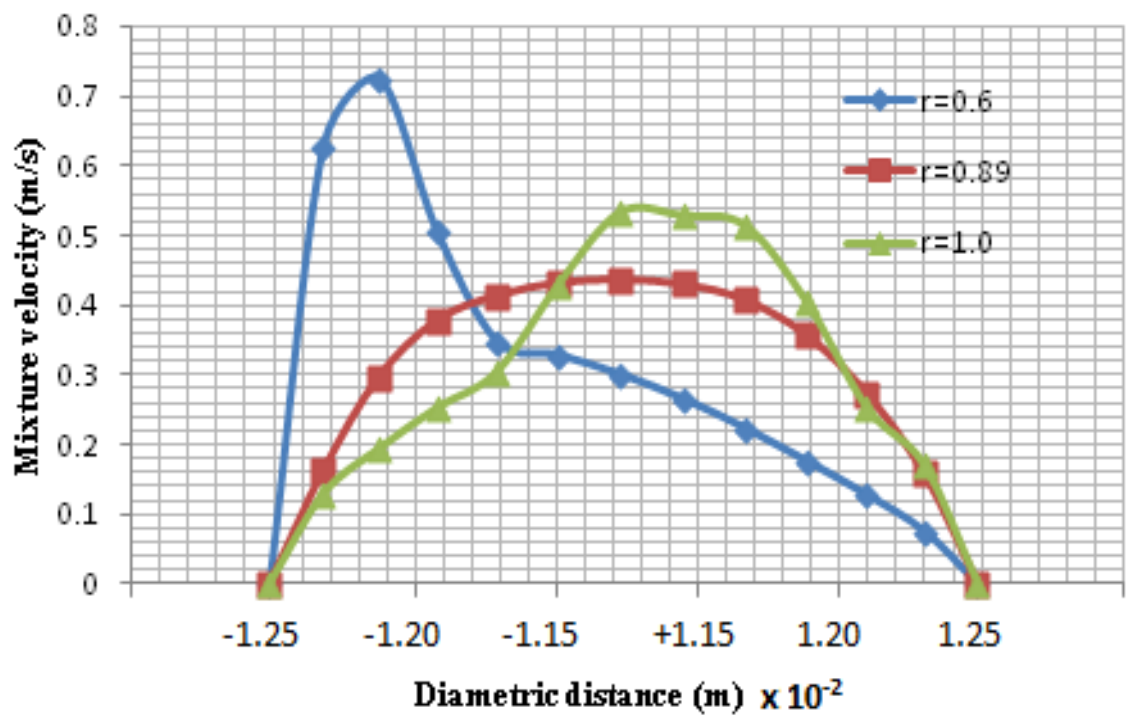

Figure 5. Density ratio affecting the diametric variation of mixture velocity 
International Journal of Mathematical, Engineering and Management Sciences

Vol. 5, No. 4, 602-613, 2020

https://doi.org/10.33889/IJMEMS.2020.5.4.049

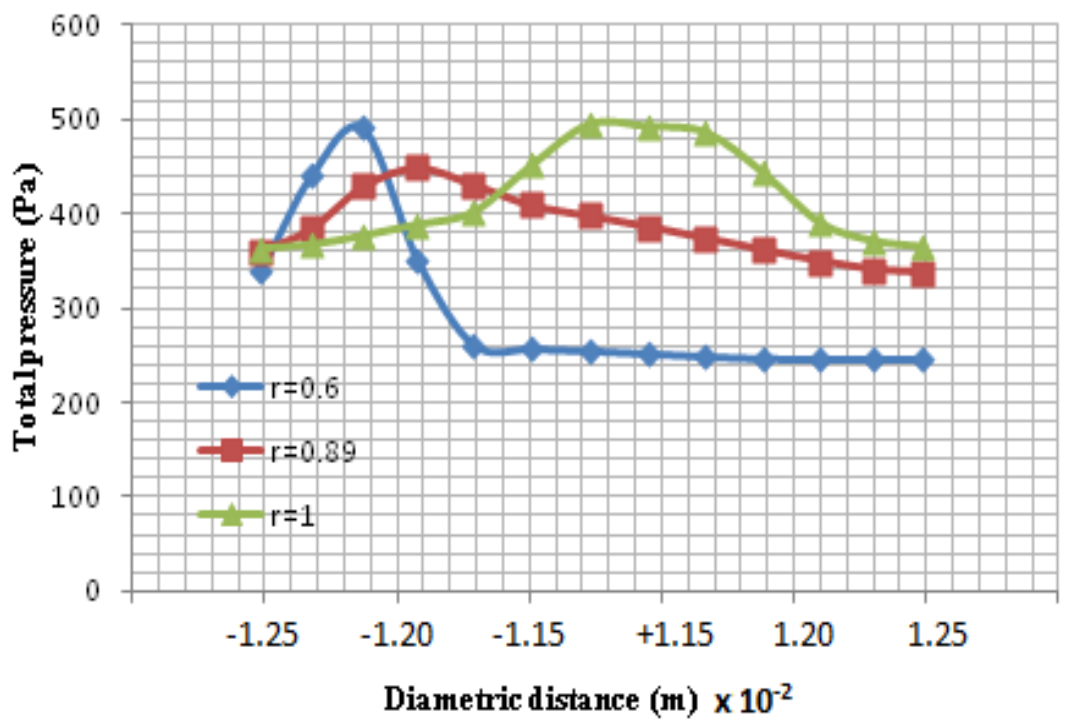

Figure 6. Density ratio affecting the diametric variation of total pressure of mixture

Figure 7 demonstrates the oil kinematic viscosity effects of oil on the diametric variation of mixture velocity. It is observed that the velocity is not a function of kinematic viscosity of oil. All the three curves are parabolic in nature and almost overlapping on each other. No change in the maximum value of velocity is also observed. Further, the Figure 8 demonstrates the consequences of the kinematic viscosity variations on the total pressure of mixture, diametrically. It is observed that total pressure is higher at higher values of kinematic viscosity. For kinematic viscosity of $1.21 \mathrm{x}$ $10^{-04}$ the total pressure varies in the range of $350 \mathrm{~Pa}$ to $450 \mathrm{~Pa}$, whereas further decrease in kinematic viscosity significantly decreases the total pressure of mixture. Pressure generally lies within 100 $\mathrm{Pa}$ at lower values as seen from graph. At lower kinematic viscosity of oil, not any significant change in the pressure variation is found. The curves are almost overlapping at lower values of kinematic viscosity of oil.

Figure 9 demonstrates the variation of mixture velocity due to changes in surface tension, diametrically. The trend for variation is almost similar for all the three values of surface tension. At a particular value of surface tension, the velocity increases first from zero value, attains maxima and then decreases. In the bottom portion of pipe, which corresponds to water phase region the curves, are very much steep whereas in the top portion of the pipe, which corresponds to oil phase region, the curves are gradual. With the increase in surface tension the curves in the water phase region becomes steeper. The mixture velocities are higher at lower values of surface tension for oil phase region. The maximum velocity does not follow any particular trend with surface tension whereas in the water phase region higher velocities are observed at higher values of surface tension, though the variation ceases after certain value of surface tension. Figure 10 shows the effect of variation of surface tension on the diametric variation of total pressure. The figure shows that there is considerable variation of total pressure of mixture with the surface tension. With the increase in surface tension, there is an increase in total pressure of mixture. The maximum values of pressure are 449.21 Pa, $510 \mathrm{~Pa}$ and $571 \mathrm{~Pa}$ for surface tension values of $0.024 \mathrm{~N} / \mathrm{m}, 0.043 \mathrm{~N} / \mathrm{m}$ and 0.0622 $\mathrm{N} / \mathrm{m}$ respectively. 
International Journal of Mathematical, Engineering and Management Sciences

Vol. 5, No. 4, 602-613, 2020

https://doi.org/10.33889/IJMEMS.2020.5.4.049

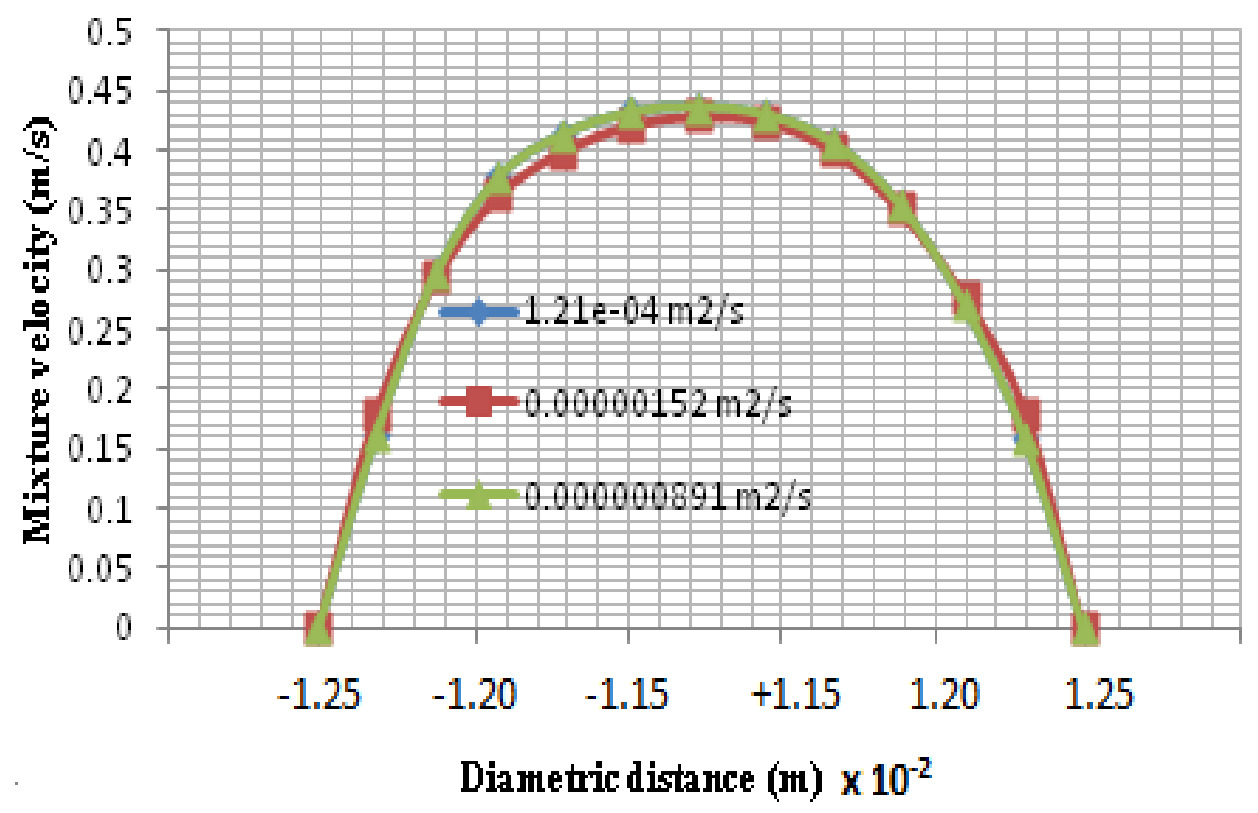

Figure 7. Oil phase kinematic viscosity changes affecting the mixture velocity

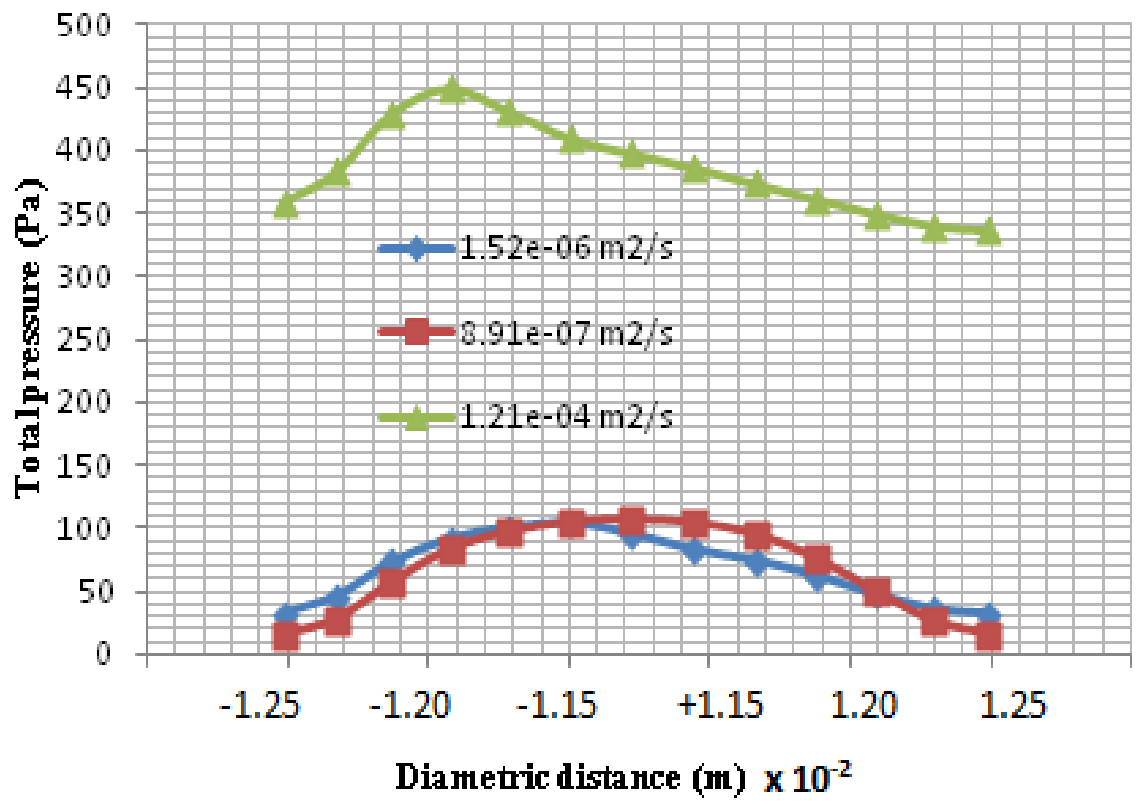

Figure 8. Oil phase kinematic viscosity changes affecting total pressure of mixture 
International Journal of Mathematical, Engineering and Management Sciences

Vol. 5, No. 4, 602-613, 2020

https://doi.org/10.33889/IJMEMS.2020.5.4.049

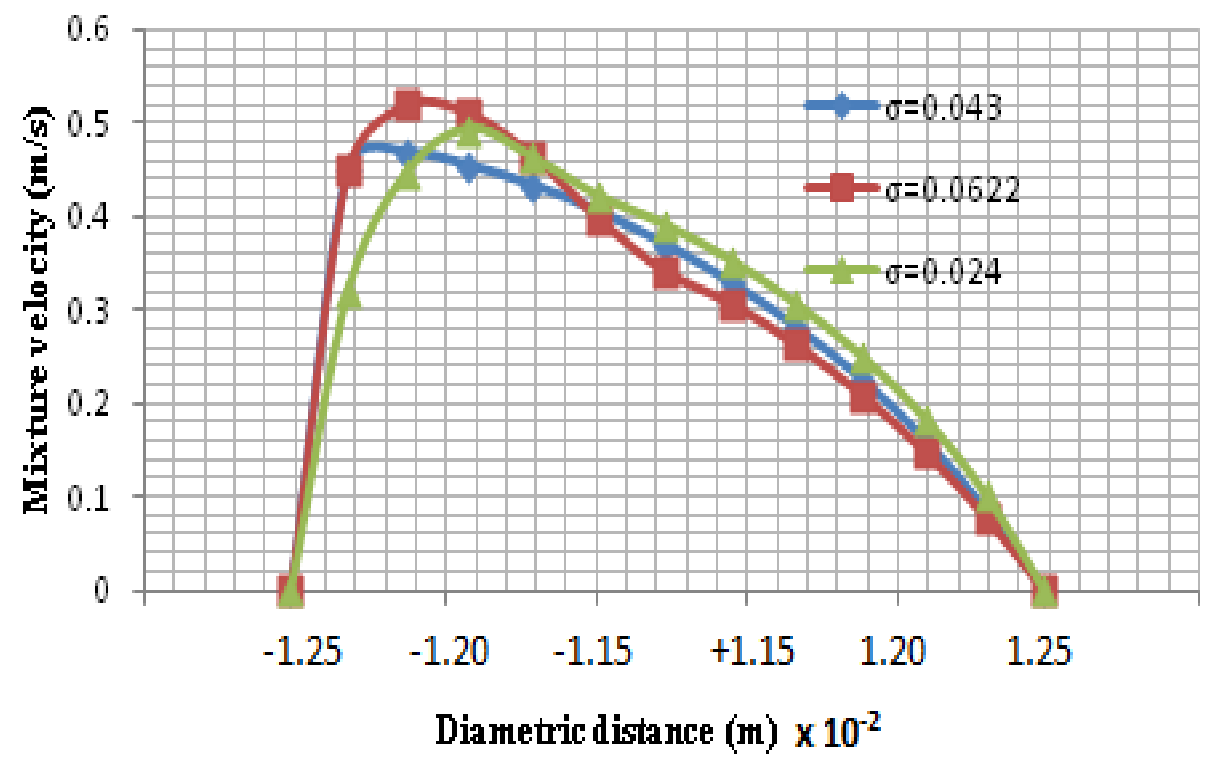

Figure 9. Surface tension affecting the diametric variation of mixture velocity

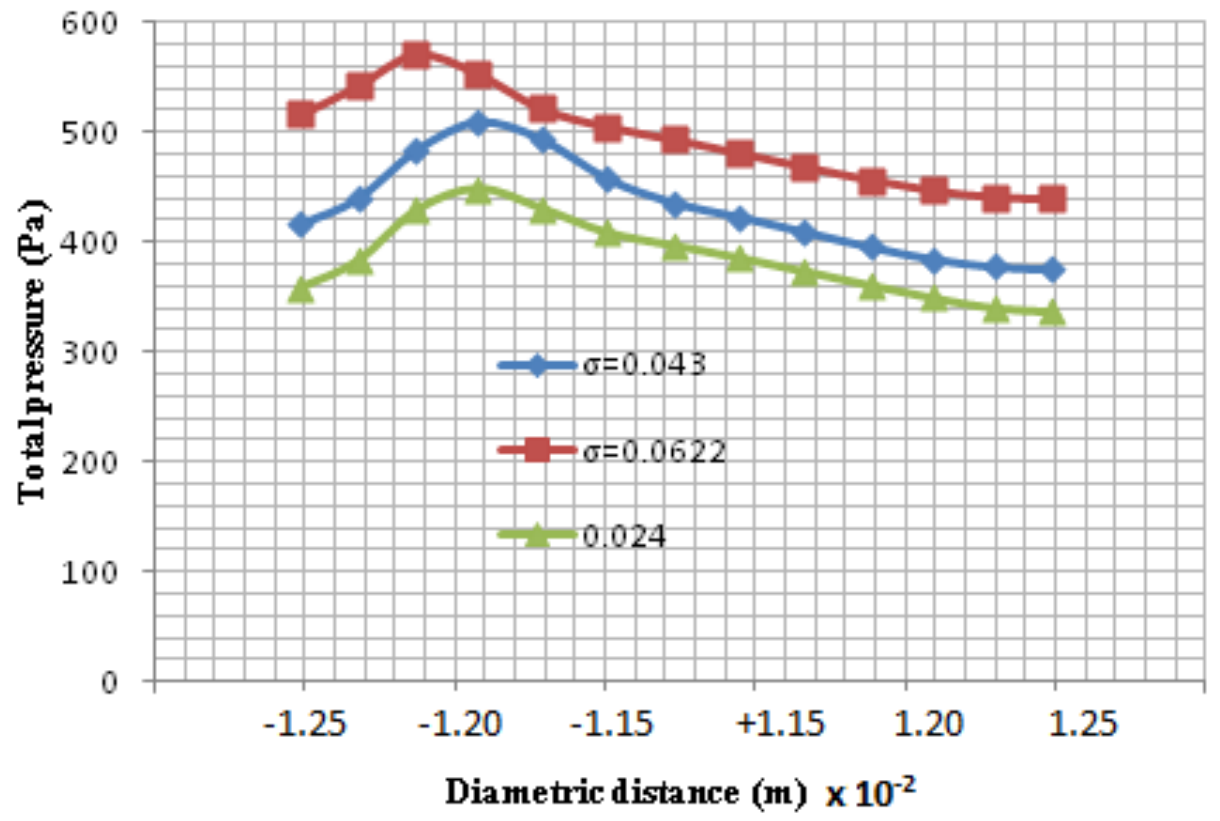

Figure 10. Surface tension affecting the diametric variation of total pressure of mixture

\section{Conclusions}

Attempts have been made to investigate the effect of density ratio of fluids, kinematic viscosity of oil and surface tension on the diametric velocity and total pressure distribution in the oil-water two phase stratified flow. In each case, three sub cases have been considered to predict the effect of 
variation of each parameter. CLSVOF have been successfully implemented to capture the interface. The computational works shows satisfactory agreement with the experimental work of Elseith (2001). It is observed that the mixture velocity is mostly influenced by density of fluids and surface tension whereas remains almost neutral to kinematic viscosity of oil. At higher values of density ratio, the diametric variations of velocity are observed to be more gradual and the maximum value of velocity is observed at higher diametric position. Velocity attains maximum value at low-density ratio. This can be attributed to the fact that as the density ratio decreases the lighter phase moves faster which causes the mixture velocity to increase. Similarly, at higher density ratios total pressure decreases with increase in the diametric distance at the top portion of channel. Maximum value of pressure shifts to a higher diametric distance with the increase in density ratio. The total pressure of the mixture is found be higher at higher values of kinematic viscosity of oil and at lower values not much difference is observed in the diametric variation of total pressure. Surface tension is found be the most influencing parameter affecting total pressure of mixture. It is observed that increase in surface tension causes an increase in pressure of mixture. Thus, these parameters must be taken care of during the design of transportation pipelines in oil industries for safe operations. The findings could be useful during such designs.

\section{Conflict of Interest}

The authors confirm that there is no conflict of interest to declare for this publication.

\section{Acknowledgment}

Authors acknowledge NIT Raipur (CG), India for extending computational and library support.

\section{References}

ANSYS Fluent Theory Guide (2012), ANSYS Inc. USA.

Avila, R.P.D., \& Rodriguez, O.M.H. (2014). Numerical predictions in wavy-stratified viscous oil-water flow in horizontal pipe. Proceedings of the International Conference on Heat Transfer and Fluid Flow, paper no. 204(1-6). Prague, Czech Republic.

Ayati, A.A., Kolaas, J., Jensen, A., \& Johnson, G.W. (2014). A PIV investigation of stratified gas-liquid flow in a horizontal pipe. International Journal of Multiphase Flow, 61, 129-143.

Ayati, A.A., Kolaas, J., Jensen, A., \& Johnson, G.W. (2015). Combined simultaneous two-phase PIV and interface elevation measurements in stratified gas/liquid pipe flow. International Journal of Multiphase Flow, 74, 45-58.

Das, S., Gada, V.H., \& Sharma, A. (2015). Analytical and level set method-based numerical study for twophase stratified flow in a pipe. Numerical Heat Transfer, Part A: Applications, 67(11), 1253-1281.

Datta, D., Gada, V.H., \& Sharma, A. (2011). Analytical and level-set method-based numerical study for twophase stratified flow in a plane channel and a square duct. Numerical Heat Transfer, Part A: Applications, 60(4), 347-380.

Desamala, A.B., Dasamahapatra, A.K., \& Mandal, T.K. (2014). Oil-water two-phase flow characteristics in horizontal pipeline-a comprehensive CFD study. International Journal of Chemical, Molecular, Nuclear, Materials and Metallurgical Engineering, World Academy of Science, Engineering and Technology, 8(4), 360-364. 
Dewangan, S.K., Senapati, S.K., \& Deshmukh, V. (2020). CFD prediction of oil-water two-phase stratified flow in a horizontal channel: coupled level set - VOF approach. Sigma Journal of Engineering and Natural Sciences, 38(1), 1-19.

Elseth, G. (2001). An experimental study of oil / water flow in horizontal pipes. The Norwegian University of Science and Technology (NTNU) for the degree of Dr. Ing.

Gada, V.H., \& Sharma, A. (2011). On a novel dual-grid level-set method for two-phase flow simulation. Numerical Heat Transfer, Part B: Fundamentals, 59(1), 26-57.

Gada, V.H., \& Sharma, A. (2009). On derivation and physical interpretation of level set method-based equations for two-phase flow simulations. Numerical Heat Transfer, Part B: Fundamentals, 56(4), $307-$ 322.

Gada, V.H., \& Sharma, A. (2012). Analytical and level-set method based numerical study on oil-water smooth/wavy stratified-flow in an inclined plane-channel. International Journal of Multiphase Flow, 38(1), 99-117.

Goldstein, A., Ullmann, A., \& Brauner, N. (2015). Characteristics of stratified laminar flows in inclined pipes. International Journal of Multiphase Flow, 75, 267-287.

Joyce, G., \& Soliman, H.M. (2016). Pressure drop for two-phase mixtures combining in a tee junction with wavy flow in the combined side. Experimental Thermal and Fluid Science, 70, 307-315.

Lee, S., Euh, D.-J., Kim, S., \& Song, C.-H. (2015). Quantitative observation of co-current stratified twophase flow in a horizontal rectangular channel. Nuclear Engineering and Technology, 47(3), 267-283.

Li, H.Y., Yap, Y.F., Lou, J., \& Shang, Z. (2015). Numerical modelling of three-fluid flow using the level-set method. Chemical Engineering Science, 126, 224-236.

Rodriguez, O.M.H., \& Baldani, L.S. (2012). Prediction of pressure gradient and holdup in wavy stratified liquid-liquid inclined pipe flow. Journal of Petroleum Science and Engineering, 96, 140-151.

Senapati, S.K., \& Dewangan, S.K. (2017). Comparison of performance of different multiphase models in predicting stratified flow. Computational Thermal Sciences: An International Journal, 9(6), 529-539.

Yap, Y.F., Chai, J.C., Toh, K.C., \& Wong, T.N. (2006). Modeling the flows of two immiscible fluids in a three-dimensional square channel using the level-set method. Numerical Heat Transfer, Part A: Applications: An International Journal of Computation and Methodology, 49(9), 893-904. 